Check for updates

Cite this: Phys. Chem. Chem. Phys.,

2021, 23, 4394

Received 11th December 2020

Accepted 4th February 2021

DOI: 10.1039/d0cp06414a

rsc.li/pccp

\title{
Shock wave and modelling study of the dissociation kinetics of $\mathrm{C}_{2} \mathrm{~F}_{5} \mathrm{I} \dagger$
}

\author{
C. J. Cobos, ${ }^{a}$ L. Sölter, ${ }^{b}$ E. Tellbach ${ }^{b}$ and J. Troe (D) $* b c$
}

\begin{abstract}
The thermal dissociation of $\mathrm{C}_{2} \mathrm{~F}_{5} \mathrm{I}$ was studied in shock waves monitoring UV absorption signals from the reactant $\mathrm{C}_{2} \mathrm{~F}_{5} \mathrm{l}$ and later formed reaction products such as $C F, \mathrm{CF}_{2}$, and $\mathrm{C}_{2} \mathrm{~F}_{4}$. Temperatures of $950-$ $1500 \mathrm{~K}$, bath gas concentrations of $[\mathrm{Ar}]=3 \times 10^{-5}-2 \times 10^{-4} \mathrm{~mol} \mathrm{~cm}^{-3}$, and reactant concentrations of 100-500 ppm $\mathrm{C}_{2} \mathrm{~F}_{5} \mathrm{l}$ in Ar were employed. Absorption-time profiles were recorded at selected wavelengths in the range 200-280 nm. It was found that the dissociation of $\mathrm{C}_{2} \mathrm{~F}_{5} \mathrm{I} \rightarrow \mathrm{C}_{2} \mathrm{~F}_{5}+$ I was followed by the dissociation $\mathrm{C}_{2} \mathrm{~F}_{5} \rightarrow \mathrm{CF}_{2}+\mathrm{CF}_{3}$, before the dimerization reactions $2 \mathrm{CF}_{2} \rightarrow \mathrm{C}_{2} \mathrm{~F}_{4}$ and $2 \mathrm{CF}_{3} \rightarrow \mathrm{C}_{2} \mathrm{~F}_{6}$ and a reaction $\mathrm{CF}_{2}+\mathrm{CF}_{3} \rightarrow \mathrm{CF}+\mathrm{CF}_{4}$ set in. The combination of iodine atoms with $\mathrm{C}_{2} \mathrm{~F}_{5}$ and $\mathrm{CF}_{3}$ had also to be considered. The rate constant of the primary dissociation of $\mathrm{C}_{2} \mathrm{~F}_{5}$ l was analyzed in the framework of statistical unimolecular rate theory accompanied by a quantum-chemical characterization of molecular parameters. Rates of secondary reactions were modelled as well. Experimental rate constants for the dissociations of $\mathrm{C}_{2} \mathrm{~F}_{5}$ l and $\mathrm{C}_{2} \mathrm{~F}_{5}$ agreed well with the modelling results. The comparably slow dimerization $2 \mathrm{CF}_{2} \rightarrow \mathrm{C}_{2} \mathrm{~F}_{4}$ could be followed both by monitoring reactant $\mathrm{CF}_{2}$ and product $\mathrm{C}_{2} \mathrm{~F}_{4}$ absorption signals, while $\mathrm{CF}_{3}$ dimerization was too fast to be detected. A competition between the dimerization reactions of $\mathrm{CF}_{2}$ and $\mathrm{CF}_{3}$, the recombination of $\mathrm{CF}_{2}$ and $\mathrm{CF}_{3}$ forming $\mathrm{C}_{2} \mathrm{~F}_{5}$, and $C F$-forming processes like $\mathrm{CF}_{2}+\mathrm{CF}_{3} \rightarrow \mathrm{CF}+\mathrm{CF}_{4}$ finally was discussed.
\end{abstract}

\section{Introduction}

$$
\mathrm{C}_{2} \mathrm{~F}_{5} \rightarrow \mathrm{CF}_{2}+\mathrm{CF}_{3} \quad \Delta H_{0}^{\circ}=238.1 \mathrm{~kJ} \mathrm{~mol}^{-1}
$$

The unimolecular dissociation of perfluoroethyl iodide

$$
\mathrm{C}_{2} \mathrm{~F}_{5} \mathrm{I} \rightarrow \mathrm{C}_{2} \mathrm{~F}_{5}+\mathrm{I} \quad \Delta H_{0}^{\circ}=234.2 \mathrm{~kJ} \mathrm{~mol}^{-1}
$$

is of interest for several reasons. On the one hand, like other perfluoroalkyl iodides, $\mathrm{C}_{2} \mathrm{~F}_{5} \mathrm{I}$ may be of technical use replacing chlorine- and bromine-containing halons, the latter leading to ozone depletion (e.g., ref. $1-4 ; \Delta H_{0}^{\circ}$ values in the present article are taken from ref. 5 and 6 , except for $\mathrm{C}_{2} \mathrm{~F}_{5} \mathrm{I}$ and $\mathrm{C}_{2} \mathrm{~F}_{4} \mathrm{I}$ whose values are estimated by quantum-chemical calculations). On the other hand, it has interesting kinetic aspects. These are the issue of the present article.

There is, at first, the rate of the unimolecular dissociation of $\mathrm{C}_{2} \mathrm{~F}_{5} \mathrm{I}$. Next, like the thermal dissociation of $\left(\mathrm{C}_{2} \mathrm{~F}_{5}\right)_{3} \mathrm{~N}$ leading to $3 \mathrm{C}_{2} \mathrm{~F}_{5}+\mathrm{N},{ }^{7}$ reaction (1) is a precursor for $\mathrm{C}_{2} \mathrm{~F}_{5}$ which dissociates by the reaction

\footnotetext{
${ }^{a}$ INIFTA, Facultad de Ciencias Exactas, Universidad Nacional de La Plata, CONICET, Argentina. E-mail: juergen.troe@mpibpc.mpg.de

${ }^{b}$ Institut für Physikalische Chemie, Universität Göttingen, Tammannstr. 6, D-37077 Göttingen, Germany

${ }^{c}$ Max-Planck-Institut für biophysikalische Chemie, Am Fassberg 11, D-37077 Göttingen, Germany

$\dagger$ Electronic supplementary information (ESI) available. See DOI: 10.1039/ d0cp06414a
}

Under typical shock tube conditions, the products $\mathrm{CF}_{2}$ and $\mathrm{CF}_{3}$ of reaction (2) decompose much more slowly than $\mathrm{C}_{2} \mathrm{~F}_{5} \mathrm{I}$ and $\mathrm{C}_{2} \mathrm{~F}_{5}$, see below. Instead of dissociating, they dimerize by the reactions

$$
\begin{aligned}
& 2 \mathrm{CF}_{2} \rightarrow \mathrm{C}_{2} \mathrm{~F}_{4} \quad \Delta H_{0}^{\circ}=-279.1 \mathrm{~kJ} \mathrm{~mol}^{-1} \\
& 2 \mathrm{CF}_{3} \rightarrow \mathrm{C}_{2} \mathrm{~F}_{6} \quad \Delta H_{0}^{\circ}=-389.4 \mathrm{~kJ} \mathrm{~mol}^{-1}
\end{aligned}
$$

$\mathrm{CF}$ radicals could be formed in reactions like

$$
\mathrm{CF}_{2}+\mathrm{CF}_{3} \rightarrow \mathrm{CF}+\mathrm{CF}_{4} \quad \Delta H_{0}^{\circ}=-25.4 \mathrm{~kJ} \mathrm{~mol}^{-1}
$$

which would lead to the stable product $\mathrm{CF}_{4}$; $\mathrm{CF}$ might dimerize as well, forming the thermally stable $\mathrm{C}_{2} \mathrm{~F}_{2}\left(\right.$ or $\left.\mathrm{C}_{2} \mathrm{~F}+\mathrm{F}\right)$, see below. The rate constants of the various steps in the decomposition mechanism of $\mathrm{C}_{2} \mathrm{~F}_{5} \mathrm{I}$ play a central role for the understanding of halon dissociation in general (see, e.g., ref. 8). It, therefore, appears worthwhile to study $\mathrm{C}_{2} \mathrm{~F}_{5} \mathrm{I}$ decomposition in detail.

While the unimolecular dissociations of $\mathrm{CF}_{3} \mathrm{I}$ and $\mathrm{C}_{3} \mathrm{~F}_{7} \mathrm{I}$ have been investigated extensively (see, e.g., the shock wave and modelling studies of ref. 3,9 , and 10 for $\mathrm{CF}_{3} \mathrm{I}$ and of ref. 4 for $\mathrm{C}_{3} \mathrm{~F}_{7} \mathrm{I}$ ), such work is lacking for $\mathrm{C}_{2} \mathrm{~F}_{5} \mathrm{I}$. There have been indirect isothermal, steady-state, ${ }^{11,12}$ and $\mathrm{CO}_{2}$-laser induced ${ }^{11}$ pyrolysis experiments at moderate temperatures. To our knowledge, 
however, only a single high-temperature shock wave study has been performed for $\mathrm{C}_{2} \mathrm{~F}_{5} \mathrm{I}^{13}$ This used the chemiluminescence process $\mathrm{I}+\mathrm{I} \rightarrow \mathrm{I}_{2}+\mathrm{h} \nu$ to conclude on reaction (1). Because high reactant concentrations $\left(0.2-1 \%\right.$ of $\mathrm{C}_{2} \mathrm{~F}_{5} \mathrm{I}$ in $\left.\mathrm{Ar}\right)$ were employed, secondary reactions such as

$$
\mathrm{C}_{2} \mathrm{~F}_{5}+\mathrm{C}_{2} \mathrm{~F}_{5} \mathrm{I} \rightarrow \mathrm{C}_{2} \mathrm{~F}_{6}+\mathrm{C}_{2} \mathrm{~F}_{4} \mathrm{I} \quad \Delta H_{0}^{\circ}=-24.5 \mathrm{~kJ} \mathrm{~mol}^{-1}
$$

or

$$
1+\mathrm{C}_{2} \mathrm{~F}_{5} \mathrm{I} \rightarrow \mathrm{C}_{2} \mathrm{~F}_{5}+\mathrm{I}_{2} \quad \Delta H_{0}^{\circ}=85.4 \mathrm{~kJ} \mathrm{~mol}^{-1}
$$

(reaction (6) followed by the fast dissociation of $\mathrm{C}_{2} \mathrm{~F}_{4} \mathrm{I}$ to $\mathrm{C}_{2} \mathrm{~F}_{4}+\mathrm{I}$ and reaction (7) followed by the dissociation of $I_{2}$ ) were suggested to form the I atoms which then were used for detection. Other secondary reactions could not be identified, partly because the also recorded UV absorptions of the parent molecules and reaction products were found to be superimposed. As we have studied UV absorptions of possible reaction products separately before, we started a new approach to $\mathrm{C}_{2} \mathrm{~F}_{5} \mathrm{I}$ dissociation in shock waves, analyzing superimposed absorption signals from reactants and products in the UV. In comparison to ref. 13 , we were able to reduce the reactant concentrations in the shock waves down to $100 \mathrm{ppm}$ in $\mathrm{Ar}$, such that mechanistic aspects of the decomposition could be further investigated under simpler conditions.

The present work should also be seen in relation to dissociation studies of $\mathrm{C}_{2} \mathrm{~F}_{5} \mathrm{I}$ using other excitation techniques. The UV photolysis of $\mathrm{C}_{2} \mathrm{~F}_{5} \mathrm{I}$, e.g., has attracted attention as a fast, direct, dissociation process with high yields of excited ${ }^{2} \mathrm{P}_{1 / 2}$ iodine atoms (e.g., ref. 14-17). The latter was considered useful for the construction of iodine photodissociation lasers (e.g., ref. 18 and 19). The fast dissociation of $\mathrm{C}_{2} \mathrm{~F}_{4} \mathrm{I}$ to $\mathrm{C}_{2} \mathrm{~F}_{4}+\mathrm{I}$, which had been suggested to follow reaction (6), ${ }^{13}$ has also been accessible. ${ }^{20} \mathrm{UV}$ laser flash photolysis and IR multiphoton excitation studies of $\mathrm{C}_{2} \mathrm{~F}_{5} \mathrm{I}$ led to information ${ }^{21,22}$ on the reverse of reaction (1) near room temperature, i.e. to the recombination

$$
\mathrm{C}_{2} \mathrm{~F}_{5}+\mathrm{I} \rightarrow \mathrm{C}_{2} \mathrm{~F}_{5} \mathrm{I} \quad \Delta H_{0}^{\circ}=-234.2 \mathrm{~kJ} \mathrm{~mol}^{-1}
$$

It was the aim of the present work to shed more light on the mechanism of $\mathrm{C}_{2} \mathrm{~F}_{5} \mathrm{I}$ decomposition under high-temperature and low reactant concentration conditions. A theoretical modelling of the falloff curves for the unimolecular dissociation of $\mathrm{C}_{2} \mathrm{~F}_{5} \mathrm{I}$ and its reverse reaction (8) was considered helpful for an analysis of the experimental results. As the present work uses UV absorption spectroscopy of the parent molecules and reaction products, quantitative knowledge of several hightemperature absorption coefficients was required. Such information was available from earlier publications referred to later. More information on absorption coefficients of $\mathrm{C}_{2} \mathrm{~F}_{5} \mathrm{I}$ has been described recently. ${ }^{23}$ As reaction (5) may lead to the formation of $\mathrm{CF}$, the dimerization of this species, forming $\mathrm{C}_{2} \mathrm{~F}_{2}$ (or leading to $\mathrm{C}_{2} \mathrm{~F}+\mathrm{F}$ ), was also modelled. Likewise, rate constants of other possible secondary reactions such as reactions (6) and (7) were inspected.

\section{Experimental technique and results}

Mixtures of 100 and 500 ppm of $\mathrm{C}_{2} \mathrm{~F}_{5} \mathrm{I}$ in $\mathrm{Ar}$ were heated in shock waves. The mixtures $\left(\mathrm{C}_{2} \mathrm{~F}_{5} \mathrm{I}\right.$ from abcr with $99 \%$ purity and $\mathrm{Ar}$ from Air Liquide with $99.9999 \%$ purity) were prepared in vessels outside the shock tube before being introduced into the tube. The used tube (length of the test section $4.15 \mathrm{~m}$ and inner diameter $9.4 \mathrm{~cm}$ ) has been described before (e.g. ref. 5, 10, and 23-34). The progress of the reaction was followed through windows placed into the wall of the tube, $5 \mathrm{~cm}$ in front of the reflecting end plate. Absorption measurements were made with a high pressure Xe arc lamp (Osram XBO $150 \mathrm{~W} / 4$ ), quartz monochromator (Zeiss M3), photomultiplier, and data acquisition arrangement. Absorption-time profiles were recorded behind incident and reflected waves. The available time for measurements behind the reflected shock was about $1.5 \mathrm{~ms}$. As the observed spectra were all continuous or quasi-continuous, broad spectral widths of about $\pm 1 \mathrm{~nm}$ could be used. Selected wavelengths from the range 200-280 nm were monitored. Temperatures for kinetic measurements were between 950 and $1500 \mathrm{~K}$, bath gas concentrations $\left[\mathrm{Ar}\right.$ ] between $3 \times 10^{-5}$ and $2 \times 10^{-4} \mathrm{~mol} \mathrm{~cm}^{-3}$.

The experiments led to a diversity of absorption-time profiles. Representative examples are shown in Fig. 1-5. The analysis of the signals used high-temperature absorption cross sections for $\mathrm{C}_{2} \mathrm{~F}_{5} \mathrm{I}$ and $\mathrm{C}_{2} \mathrm{~F}_{5}$ from ref. 23, for $\mathrm{C}_{2} \mathrm{~F}_{4}$ from ref. 24, for $\mathrm{CF}_{3} \mathrm{I}$ (formed by combination of $\mathrm{CF}_{3}$ with $\mathrm{I}$ ) from ref. 10 and 25 , for $\mathrm{CF}_{3}$ from ref. 23 and 26, for $\mathrm{CF}_{2}$ from ref. 24 and 27 , and for CF from ref. 28 (representative absorption cross sections at a typical temperature of $1200 \mathrm{~K}$, for orientation, are given in Table 1). In addition, modelled rate constants such as summarized in Table 2 (for their determination, see the following sections and the ESI $\dagger$ ) facilitated the analysis. Besides the dissociation reactions, their reverse recombination processes had also to be included. All dissociation and recombination reactions were in their falloff ranges such that suitable falloff expressions of the rate

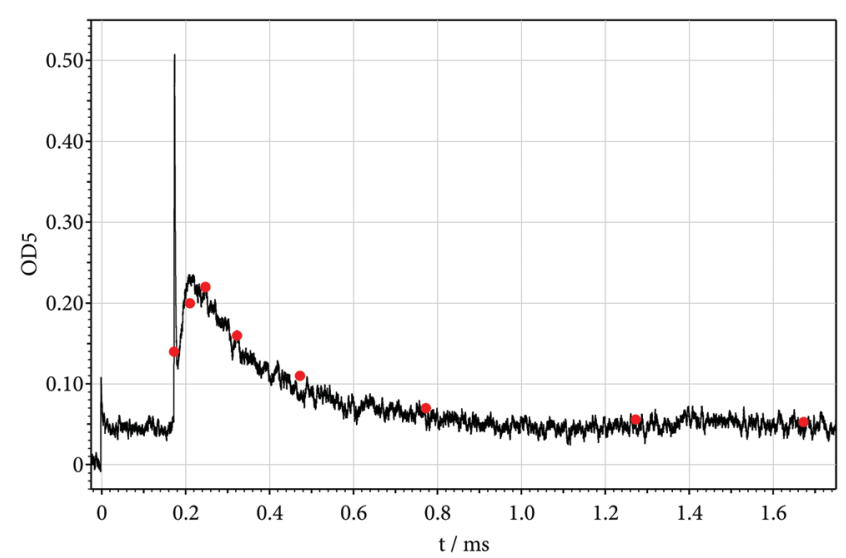

Fig. 1 Absorption-time profile recorded at $268.5 \mathrm{~nm}$ in the decomposition of $\mathrm{C}_{2} \mathrm{~F}_{5}$ l (reflected shock wave: $T=1195 \mathrm{~K}, 500 \mathrm{ppm}$ of $\mathrm{C}_{2} \mathrm{~F}_{5}$ l in $\mathrm{Ar}$, $[\mathrm{Ar}]=$ $1.3 \times 10^{-4} \mathrm{~mol} \mathrm{~cm}^{-3} ; \mathrm{OD} 5=\ln \left(/ I_{0} / /\right)$ with light intensity $/$ and path length $x=$ $9.4 \mathrm{~cm}$, see text; 0 : modelled points with data from Tables $1-3, k_{5}$ fitted as $k_{5} \approx 2 \times k_{-2, \infty}$ where $k_{-2, \infty}=k_{2, \infty} / k_{2, c}$, see text). 
Table 1 Selected absorption cross sections $\sigma$ near $T=1200 \mathrm{~K}$, used for the analysis of Fig. $1-5$, see text (* upper limits, estimated for $2000 \mathrm{~K}$ )

\begin{tabular}{llll}
\hline Species & Wavelength $(\mathrm{nm})$ & $\sigma\left(\mathrm{cm}^{2}\right)$ & Ref. \\
\hline $\mathrm{C}_{2} \mathrm{~F}_{5} \mathrm{I}$ & 280 & $4.1 \times 10^{-19}$ & 23 \\
& 268.5 & $3.3 \times 10^{-19}$ & \\
$\mathrm{C}_{2} \mathrm{~F}_{4}$ & 200 & $4.5 \times 10^{-18}$ & 24 \\
$\mathrm{CF}_{2}$ & 280 & $4.2 \times 10^{-19}$ & 27 \\
& 268.5 & $2.0 \times 10^{-18}$ & \\
& 248 & $6.8 \times 10^{-18}$ & \\
$\mathrm{CF}$ & 200 & $3.3 \times 10^{-23}$ & \\
& 248 & $1.0 \times 10^{-17}$ & $28^{*}$ \\
& 200 & $7.0 \times 10^{-17}$ &
\end{tabular}

constants (with the parameters given in Table 2) had to be used. Without the mentioned spectroscopic and kinetic input parameters, an interpretation of the signals would have been considerably more difficult.

Fig. 1, first, shows a signal recorded at $268.5 \mathrm{~nm}$, i.e. at the maximum of the room temperature spectrum of $\mathrm{C}_{2} \mathrm{~F}_{5} \mathrm{I}^{14,35,36}$ The absorption steps at the arrival of the incident and reflected shocks (behind the two Schlieren peaks) allow one ${ }^{23}$ to derive the absorption coefficients of $\mathrm{C}_{2} \mathrm{~F}_{5} \mathrm{I}$ at $691 \mathrm{~K}$ (incident shock) and $1195 \mathrm{~K}$ (reflected shock; for a quantitative analysis, one has also to account for the absorption in front of the incident shock, using the known room temperature absorption coefficient). At the temperature of the reflected shock, obviously not only the disappearance of $\mathrm{C}_{2} \mathrm{~F}_{5} \mathrm{I}$ but the appearance of a more strongly absorbing reaction product is observed which then disappears on a longer time scale. The identification of this absorber can be made using the rate constants characterized in Table 2. As $k_{1}$ (close to $10^{5} \mathrm{~s}^{-1}$ ) for Fig. 1 is markedly larger than $k_{2}$ (close to $2 \times$ $10^{4} \mathrm{~s}^{-1}$ ), the decay of $\mathrm{C}_{2} \mathrm{~F}_{5} \mathrm{I}$ is too fast to be resolved and the rising signal behind the reflected shock must be attributed to

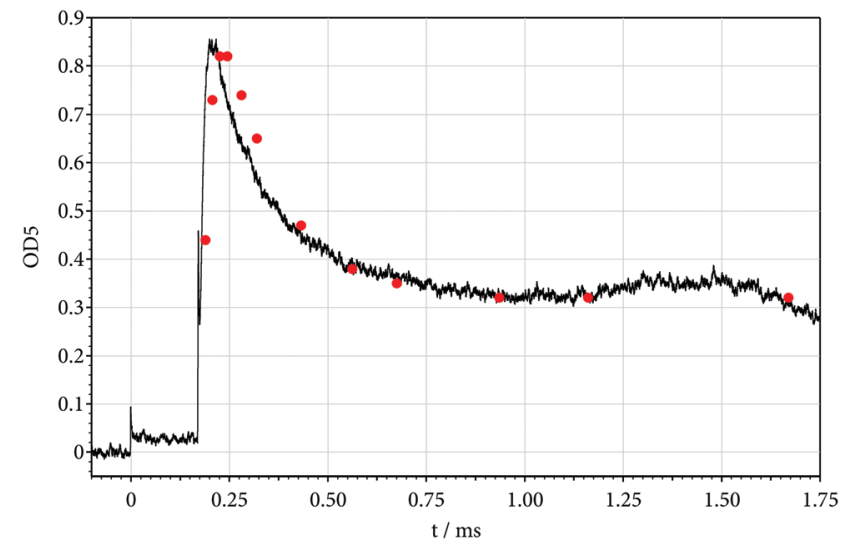

Fig. 2 As Fig. 1, but recorded at $248 \mathrm{~nm}$ (reflected shock wave: $T=1213 \mathrm{~K}$, $530 \mathrm{ppm}$ of $\mathrm{C}_{2} \mathrm{~F}_{5} \mathrm{l}$ in $\mathrm{Ar}$, [Ar] $=1.3 \times 10^{-4} \mathrm{~mol} \mathrm{~cm}^{-3}$; 0 : modelled points with data from Tables $1-3, k_{5}$ fitted as $k_{5} \approx 1.5 \times k_{-2, \infty}$ where $k_{-2, \infty}=$ $k_{2, \infty} / K_{2, c}$, see text)

$\mathrm{CF}_{2}$ from reaction (2) (the maximum of $\mathrm{CF}_{2}$ absorption of is located at $248 \mathrm{~nm},{ }^{24,27}$ but the absorption of the broad quasicontinuum with increasing temperature increasingly extends to longer wavelengths, i.e. also to $268.5 \mathrm{~nm}$ ).

Fig. 2 shows a signal recorded at $248 \mathrm{~nm}$. Under the assumption that each decomposing $\mathrm{C}_{2} \mathrm{~F}_{5} \mathrm{I}$ by reactions (1) and (2) leads to one $\mathrm{CF}_{2}$, the initial rate of increase of the absorption behind the reflected shock in Fig. 2 allows one to derive an experimental value of $k_{2}$. The detailed analysis (accounting for the Schlieren signal) indeed leads to the modelled value following from Table 2, see below. Besides the initial increase of the signal due to the formation of $\mathrm{CF}_{2}$, the decay of the signal behind the reflected shock must be explained. One finds that the decay of the $\mathrm{CF}_{2}$ signal can mostly be attributed to the

Table 2 Modelled rate constants for dissociation reactions and their equilibrium constants (limiting high pressure dissociation rate constants $k_{\infty}$ in $\mathrm{s}^{-1}$, limiting low pressure dissociation rate constants $k_{0} /[\mathrm{Ar}]$ in $\mathrm{cm}^{3} \mathrm{~mol}^{-1} \mathrm{~s}^{-1}$, and weak collision center broadening factors $F_{\text {cent }}=F_{\text {cent }}^{\text {sc }} \times 0.64$ to be used in falloff expressions from ref. 39-41, equilibrium constants $K_{\mathrm{c}}=k_{\text {dis }} / k_{\text {rec }}$ in $\mathrm{mol} \mathrm{cm}{ }^{-3}$, *: experimental adjustment of $k_{1, \infty}, k_{1,0}$, and $k_{1, \mathrm{c}}$ possible by adding a factor of $\exp (-600 \mathrm{~K} / \mathrm{T})$, see text)

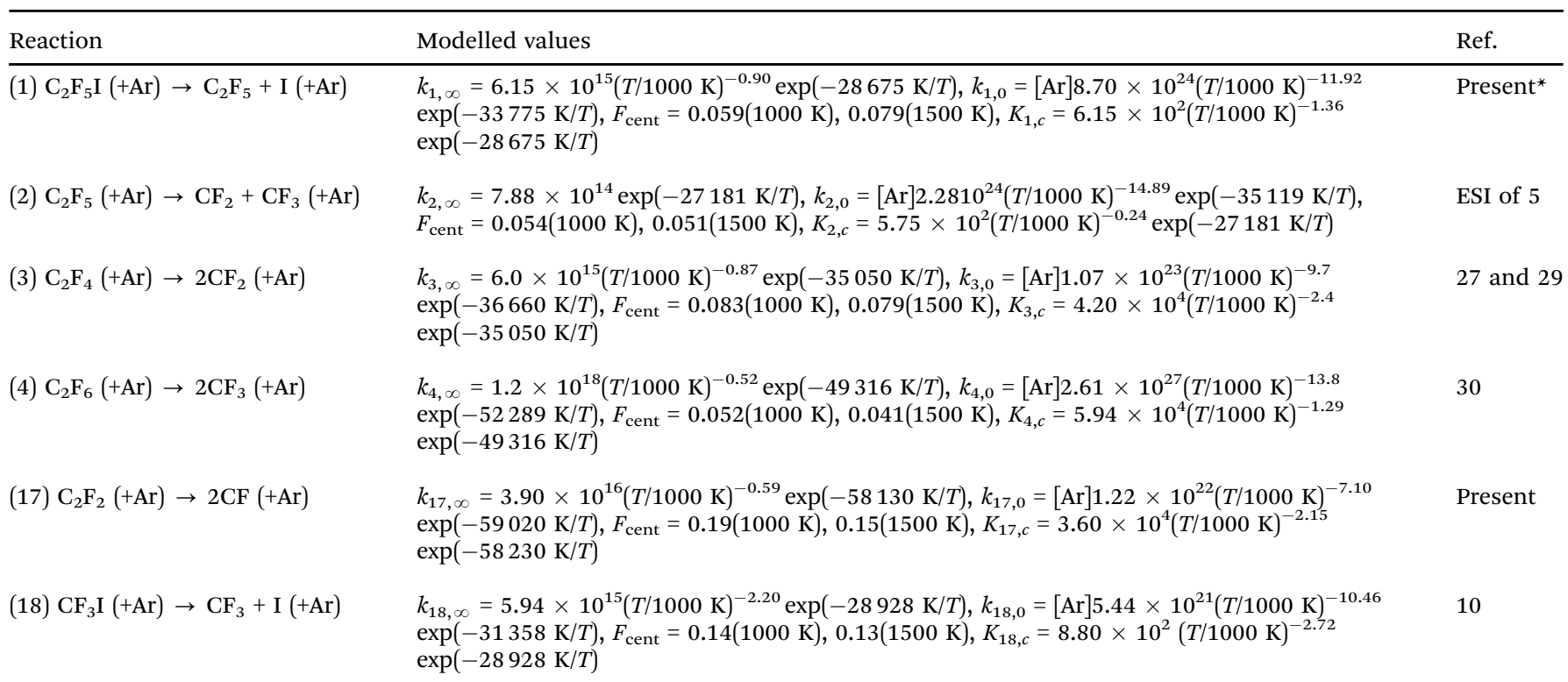




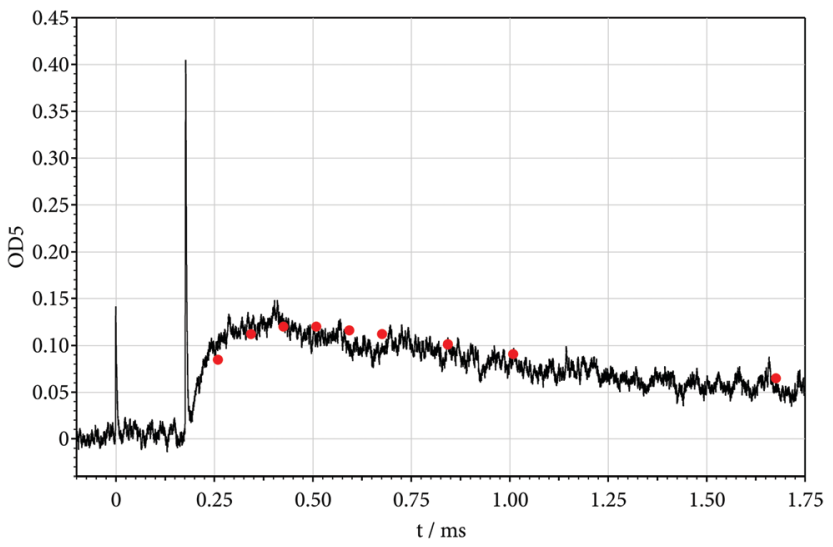

Fig. 3 As Fig. 1, but recorded at $248 \mathrm{~nm}$ (reflected shock wave: $T=1117 \mathrm{~K}$, $108 \mathrm{ppm}$ of $\mathrm{C}_{2} \mathrm{~F}_{5} \mathrm{l}$ in $\mathrm{Ar}$, and $[\mathrm{Ar}]=1.4 \times 10^{-4} \mathrm{~mol} \mathrm{~cm}{ }^{-3} ; 0$ : modelled points with data from Tables $1-3, k_{3}$ increased by a factor of 2 and $k_{5}$ fitted as $k_{5} \approx 10 \times k_{-2, \infty}$ where $k_{-2, \infty}=k_{2, \infty} / k_{2, c}$, see text).

known dimerization of $\mathrm{CF}_{2}$ (with rate constants following from Table 2). One, furthermore, observes that the maximum of the signal is markedly smaller than expected for a simple mechanism of reactions (1) and (2) alone. This is attributed to a contribution from reaction (5) which converts $\mathrm{CF}_{2}$ into less reactive species, see below.

A dependence of the $\mathrm{CF}_{2}$ signal on the reactant concentration is documented in Fig. 3 where the initial $\mathrm{C}_{2} \mathrm{~F}_{5} \mathrm{I}$ concentration has been decreased by about a factor of 5 in comparison to Fig. 1 and 2. The initial rate of $\mathrm{CF}_{2}$ formation again is well explained by that of $\mathrm{C}_{2} \mathrm{~F}_{5}$ dissociation $\left(k_{2} \approx 2 \times 10^{4} \mathrm{~s}^{-1}\right)$. The decay of the $\mathrm{CF}_{2}$ signal on the other hand is markedly slower than that of Fig. 1 and 2, indicating a more complicated kinetics of $\mathrm{CF}_{2}$ disappearance than explained by dimerization alone, see below.

While a contribution from the parent $\mathrm{C}_{2} \mathrm{~F}_{5} \mathrm{I}$ to the signal behind the reflected shock at $248 \mathrm{~nm}$ is only of minor importance and can be accounted for, one may also look for absorptions from other species. For this reason, we inspected signals at shorter wavelengths. Fig. 4 shows an example recorded at $200 \mathrm{~nm}$. At this wavelength, a

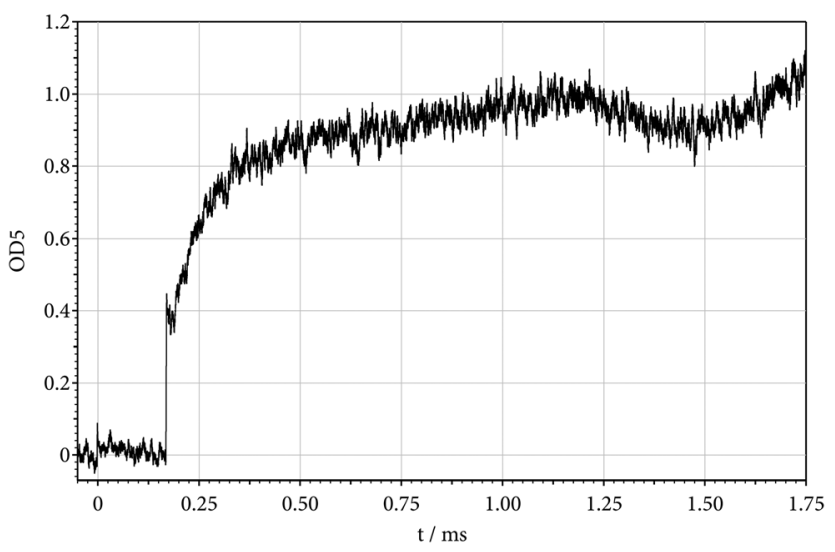

Fig. 4 As Fig. 1, but recorded at $200 \mathrm{~nm}$ (reflected shock wave at $t=0.18 \mathrm{~ms}$ : $T=1255 \mathrm{~K}, 533 \mathrm{ppm}$ of $\mathrm{C}_{2} \mathrm{~F}_{5} \mathrm{l}$ in $\mathrm{Ar}$, and $[\mathrm{Ar}]=1.2 \times 10^{-4} \mathrm{~mol} \mathrm{~cm}^{-3}$ ).

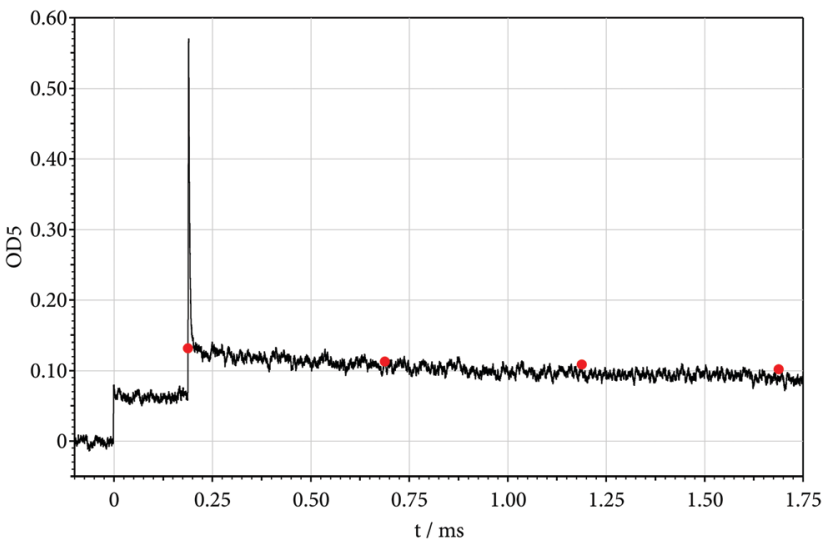

Fig. 5 As Fig. 1, but recorded at $280 \mathrm{~nm}$ (reflected shock wave: $T=970 \mathrm{~K}$, $497 \mathrm{ppm}$ of $\mathrm{C}_{2} \mathrm{~F}_{5}$ l in $\mathrm{Ar},[\mathrm{Ar}]=1.6 \times 10^{-4} \mathrm{~mol} \mathrm{~cm}{ }^{-3}$; 0 : modelled points with data from Tables $1-3, k_{1}$ and $K_{1, c}$ decreased by a factor of $\exp (-600 \mathrm{~K} / T$ ), see text).

contribution of $\mathrm{CF}_{2}$ to the signal can safely be neglected. ${ }^{24}$ Instead, the absorption from stronger absorbers, forming during the reaction here dominates. One of these can be identified as $\mathrm{C}_{2} \mathrm{~F}_{4} \cdot{ }^{24}$ First, the rise time of the signal corresponds to the dimerization of $\mathrm{CF}_{2}$ by reaction (3). ${ }^{27,29}$ Second, at higher temperatures where $\mathrm{C}_{2} \mathrm{~F}_{4}$ thermally decomposes, the final signals are consistent with the temperature dependence of the $\mathrm{C}_{2} \mathrm{~F}_{4} \Leftrightarrow 2 \mathrm{CF}_{2}$ equilibrium. ${ }^{27}$ Third, the absolute values and the wavelength dependence of the signals agree with the known results for $\mathrm{C}_{2} \mathrm{~F}_{4} \cdot{ }^{24}$ A second contribution to the signal may arise from the even stronger absorber CF formed by reactions like reaction (5). ${ }^{28}$ Unfortunately the present work could not provide more insight into the kinetics of CF radicals. It was, therefore, also not clear whether "irregularities" of the signals at late time in Fig. 2 and 4 (after about $1 \mathrm{~ms}$ ) were due to such reactions, or simply marked the end of the observation time in the shock wave experiments.

In order to record signals with contributions mostly from $\mathrm{C}_{2} \mathrm{~F}_{5} \mathrm{I}$, we finally inspected absorption-time profiles at $280 \mathrm{~nm}$, i.e. on the long-wavelength tails of the $\mathrm{C}_{2} \mathrm{~F}_{5} \mathrm{I}$ and $\mathrm{CF}_{2}$ absorption continua. Fig. 5 shows a signal recorded for a temperature lower than those used in Fig. 1-4. Here, $\mathrm{CF}_{2}$ formation is too slow to disturb the absorption signal from $\mathrm{C}_{2} \mathrm{~F}_{5} \mathrm{I}$ to a major extent, but the decay of $\mathrm{C}_{2} \mathrm{~F}_{5} \mathrm{I}$ becomes visible.

The overall mechanism of $\mathrm{C}_{2} \mathrm{~F}_{5} \mathrm{I}$ dissociation, even at reactant concentrations as low as 100 ppm in Ar, apparently was not only determined by the primary first-order dissociation of $\mathrm{C}_{2} \mathrm{~F}_{5} \mathrm{I}$, but by several secondary first- and second- order reaction steps and their reverse reactions (equilibrium constants are included in Table 2). A modelling of the corresponding rate constants appeared helpful for a start of the analysis of signals like Fig. 1-5. This modelling is described in the following section (as well as in the ESI $\dagger$ ).

\section{Modelling of rate constants for the unimolecular dissociation of $\mathrm{C}_{2} \mathrm{~F}_{5} \mathrm{I}$}

Our quantum-chemical characterization of the potential energy surface for $\mathrm{C}_{2} \mathrm{~F}_{5} \mathrm{I}$ dissociation (1) closely followed the procedure 
outlined for $\mathrm{CF}_{3} \mathrm{I}$ dissociation in ref. 10 (and its ESI) and needs not to be repeated here. The derived electronic potential for the $\mathrm{C}_{2} \mathrm{~F}_{5}-\mathrm{I}$ bond is illustrated in Fig. S1 of the present ESI. $\dagger$ The potential can be approximated by a Morse potential with a Morse parameter $\beta=1.51 \AA^{-1}$ (for $\mathrm{C}_{2} \mathrm{~F}_{5}$-I distances larger than $2.2 \AA$ ) or $\beta=1.76 \AA^{-1}$ (for $\mathrm{C}_{2} \mathrm{~F}_{5}$-I distances larger than $3.25 \AA$ ). The quanta of the bending modes of $\mathrm{C}_{2} \mathrm{~F}_{5} \mathrm{I}$, which disappear during bond-breaking, decrease exponentially with increasing $\mathrm{C}_{2} \mathrm{~F}_{5}$-I bond length (with decay parameters $\alpha=0.53( \pm 0.01) \AA^{-1}$, see Fig. S2 of the ESI $\dagger$ ). The decrease of the rotational constant $(B+C) / 2$ of the decomposing $\mathrm{C}_{2} \mathrm{~F}_{5} \mathrm{I}$ is also fitted such as illustrated in Fig. S3 of the ESI. $\dagger$ The latter is required for the determination of the centrifugal barriers which can be represented by $E_{0}(J) \approx E_{0}(J=0)+C_{\nu}[J(J+1)]^{\nu}$ with $C_{\nu}=h c \cdot 1.14 \times 10^{-3} \mathrm{~cm}^{-1}$ and $\nu=1.17$. Neglecting the anisotropy of the potential, i.e. using phase space theory (PST), high pressure recombination rate constants for reaction (8) of $k_{\mathrm{rec}, \infty}^{\mathrm{PST}}=(4-6) \times 10^{13} \mathrm{~cm}^{3} \mathrm{~mol}^{-1} \mathrm{~s}^{-1}$ are obtained between 750 and $2000 \mathrm{~K}$ (see the modelling results in Table 2). The anisotropy of the potential introduces "rigidity" and reduces $k_{\mathrm{rec}, \infty}$ to values below $k_{\mathrm{rec}, \infty}^{\mathrm{PST}}$. The classical trajectory version of the statistical adiabatic channel model (SACM/CT) of ref. 37 provides a simple approach to express this reduction as a function of the ratio $\alpha / \beta$, here shown to be about 0.3 (one notes that this ratio in the present case is somewhat below the "standard value" $0.5,{ }^{38}$ i.e. it corresponds to a comparably rigid potential). Table 3 shows the results for $k_{\text {rec, } \infty}$ which can be approximated by

$$
k_{\mathrm{rec}, \infty} \approx 1.0 \times 10^{13}(T / 1000 \mathrm{~K})^{0.46} \mathrm{~cm}^{3} \mathrm{~mol}^{-1} \mathrm{~s}^{-1}
$$

The corresponding dissociation rate constants $k_{\mathrm{dis}, \infty}$ in Table 2 are represented by

$$
k_{\mathrm{dis}, \infty} \approx 6.15 \times 10^{15}(T / 1000 \mathrm{~K})^{-0.90} \exp (-28675 \mathrm{~K} / T) \mathrm{s}^{-1}
$$

It appears worthwhile to compare the modelled high-pressure recombination rate constants for $300 \mathrm{~K}$, i.e. $k_{\mathrm{rec}, \infty}(300 \mathrm{~K}) \approx 5.5( \pm 3) \times$ $10^{12} \mathrm{~cm}^{3} \mathrm{~mol}^{-1} \mathrm{~s}^{-1}$, with the measurements from ref. 21 and 22 which led to a value of $1.2( \pm 0.4) \times 10^{13} \mathrm{~cm}^{3} \mathrm{~mol}^{-1} \mathrm{~s}^{-1}$. Within the estimated uncertainties of either approach, the results appear sufficiently close.

The calculation of the limiting low-pressure rate constant $k_{\text {dis, } 0}$ followed the procedure described in ref. 39 with the required parameters $C_{\nu}, \nu$, and $E_{0}(J)$ for the centrifugal barriers as given above (for other parameters, see the ESI $\dagger$ ). Collision efficiencies and the corresponding average (total) energies transferred per collision $\langle\Delta E\rangle$ as usual had to be estimated.

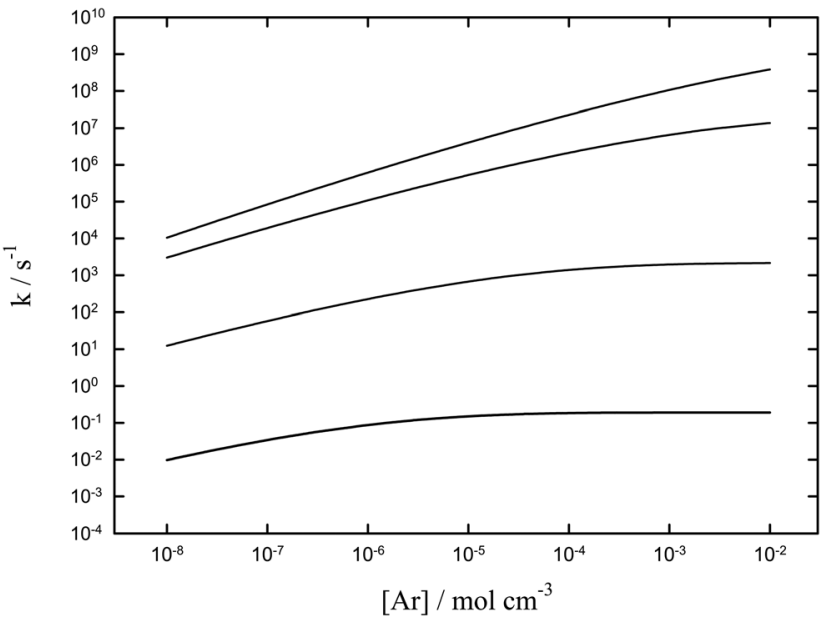

Fig. 6 Modelled falloff curves for the unimolecular dissociation of $\mathrm{C}_{2} \mathrm{~F}_{5} \mathrm{l}$ in Ar (calculations for 750, 1000, 1500, and $2000 \mathrm{~K}$ from bottom to top; see text and ESI†).

Like in previous work, we used a value of $\langle\Delta E\rangle / h c \approx-100 \mathrm{~cm}^{-1}$ for a start. This led to

$$
\begin{gathered}
k_{\mathrm{dis}, 0} \approx[\mathrm{Ar}] 8.7 \times 10^{24}(T / 1000 \mathrm{~K})^{-11.92} \\
\exp (-33775 \mathrm{~K} / T) \mathrm{cm}^{3} \mathrm{~mol}^{-1} \mathrm{~s}^{-1}
\end{gathered}
$$

Falloff expressions for the transition of $k_{1}$ from $k_{\mathrm{dis}, 0}$ to $k_{\mathrm{dis}, \infty}$ were expressed in the form proposed in ref. 39-42. The required weak collision "center broadening factors" $F_{\text {cent }}=F_{\text {cent }}^{\mathrm{sc}} \times$ 0.64 were estimated with the method of ref. 39-41. Values of $F_{\text {cent }} \approx 0.063,0.059,0.079$, and 0.12 were derived for $T / \mathrm{K}=750$, 1000, 1500, and 2000, respectively. The finally obtained falloff curves are shown in Fig. 6 . The figure well documents the shift of the falloff curves with temperature. At a bath gas concentration [Ar] $=10^{-4} \mathrm{~mol} \mathrm{~cm}^{-3}$ and $T \leq 750 \mathrm{~K}$, the reaction is close to the high-pressure limit, while it is closer to the low-pressure limit at $T \geq 1500 \mathrm{~K}$. Intermediate falloff effects thus are important for all conditions of the present work. Modelled dissociation and recombination rate constants are summarized in Table 3 . Values

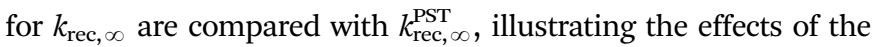
anisotropy of the potential. Furthermore, the positions of the "centers of the falloff curves" $[\mathrm{Ar}]_{\text {cent }}$ are given, i.e. the values of [Ar] for which $k_{\text {dis }, 0} \approx k_{\text {dis, } \infty}$. The increase of $[\mathrm{Ar}]_{\text {cent }}$ with increasing $T$ quantifies the shift of the falloff curves with temperature. It also appears important to estimate the uncertainty of $k_{\mathrm{dis}, \infty}$ caused by the uncertainty of the reaction enthalpy. The modelling of the signal of Fig. 5 and of the rate constants $k_{1}(T)$ described below

\begin{tabular}{|c|c|c|c|c|c|c|}
\hline$T / \mathrm{K}$ & $k_{\mathrm{rec}, \infty}^{\mathrm{PST}}$ & $k_{\mathrm{rec}, \infty}$ & $k_{\mathrm{dis}, \infty}$ & $k_{\mathrm{dis}, 0} /[\mathrm{Ar}]$ & $F_{\text {cent }}$ & {$[\mathrm{Ar}]_{\mathrm{cent}}$} \\
\hline 1000 & $4.76 \times 10^{13}$ & $1.00 \times 10^{13}$ & $2.16 \times 10^{3}$ & $1.86 \times 10^{10}$ & 0.059 & $1.2 \times 10^{-7}$ \\
\hline
\end{tabular}

Table 3 Modelled rate constants for dissociation and recombination of $\mathrm{C}_{2} \mathrm{~F}_{5} l, k_{\text {dis }}=k_{1}$ and $k_{\text {rec }}=k_{8}\left(k_{\mathrm{rec}, \infty}^{\mathrm{PST}}=k_{\mathrm{rec}}\right.$ from Phase Space Theory (PST); $k_{\mathrm{rec}, \infty}^{\mathrm{PST}}$ and $k_{\text {rec, } \infty}$ in $\mathrm{cm}^{3} \mathrm{~mol}^{-1} \mathrm{~s}^{-1} ; k_{\text {dis, }, ~}$ in s ${ }^{-1} ; k_{\text {dis, }, o} /[\mathrm{Ar}]$ in $\mathrm{cm}^{3} \mathrm{~mol}^{-1} \mathrm{~s}^{-1} ; F_{\text {cent }}$ : weak collision center broadening factors; [Ar $]_{\text {cent }}$ in mol $\mathrm{cm}^{-3}$ : centers of the falloff curves, see text) 
suggests an increase of $\Delta H_{0}^{\circ}$ by about $5 \mathrm{~kJ} \mathrm{~mol}^{-1}$ which adds a factor of about $\exp (-600 \mathrm{~K} / T)$ to eqn (10) and (11) as well as $K_{1, \mathrm{c}}$ in Table 2. Finally, it appears of interest to compare the present modelling results for $k_{1}$ with values obtained from the iodine chemiluminescence experiments of ref. 13. The values for $k_{1}$ from the latter work at $1100 \mathrm{~K}$ are about a factor of two larger than the present modelling whereas they nearly agree near $1300 \mathrm{~K}$.

\section{Modelling of rate constants for secondary reactions}

In this section we describe modelling results for reactions which may play a role as secondary processes in the decomposition mechanism of $\mathrm{C}_{2} \mathrm{~F}_{5} \mathrm{I}$. As the falloff curves for the dissociation reactions of $\mathrm{C}_{2} \mathrm{~F}_{4}, \mathrm{C}_{2} \mathrm{~F}_{5}, \mathrm{C}_{2} \mathrm{~F}_{6}$, and $\mathrm{CF}_{3} \mathrm{I}$ and their reverse recombination (or dimerization) reactions had been characterized before, they need not to be described here again (see their parameters in Table 2). We only performed a further modelling of $\mathrm{C}_{2} \mathrm{~F}_{2}$ dissociation and the reverse CF dimerization rates. These data are needed in case that $\mathrm{CF}$ is formed by some secondary reactions (details of this modelling are described in the ESI $\dagger$ and the results are included in Table 2). CF is a particularly strong absorber over the wavelength range 200$280 \mathrm{~nm}$ studied in the present work, such that eventual contributions from CF to the recorded signals had to be carefully considered. $\mathrm{CF}$, e.g., could be formed by reaction (5); highenergy dissociation channels of $\mathrm{C}_{2} \mathrm{~F}_{4}, \mathrm{C}_{2} \mathrm{~F}_{5}$, and $\mathrm{C}_{2} \mathrm{~F}_{6}$, however, could also play some role. For this reason, we determined minimum-energy path (MEP) potentials of the corresponding processes using the quantum-chemical techniques mentioned above. Fig. 7 shows the results for reaction (5) and the dissociation of $\mathrm{C}_{2} \mathrm{~F}_{5}$. The calculations first show that the MEP pathway from $\mathrm{CF}_{2}+\mathrm{CF}_{3}$ through bound $\mathrm{C}_{2} \mathrm{~F}_{5}$ to $\mathrm{CF}+\mathrm{CF}_{4}$ involves a high energy barrier (TS) of $224.6 \mathrm{~kJ} \mathrm{~mol}^{-1}$. This would rule out reaction (5) as a pathway for $\mathrm{CF}$ formation.

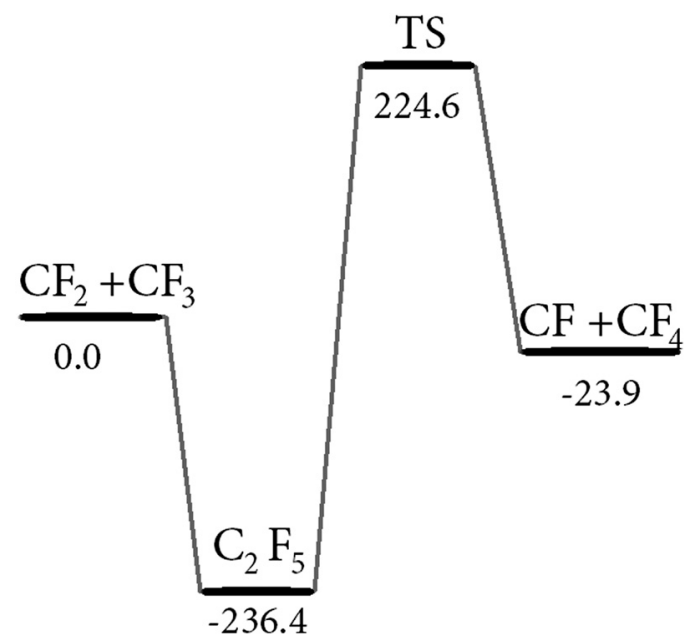

Fig. 7 Schematic energy diagram for reactions (2) and (5) (energies in $\mathrm{kJ} \mathrm{mol}^{-1}$; from ab initio composite G4 model and Intrinsic Reaction Coordinate (IRC) calculations; see text and ESI $\dagger$ ).
However, one may imagine that the exothermic reaction proceeds as a roaming radical process (analogous to processes described in ref. 43-45), skirting "outside" along the barrier of the TS and avoiding the passage of the $\mathrm{C}_{2} \mathrm{~F}_{5}$ intermediate. While this looks like an attractive possibility, its confirmation by trajectory calculations on a full potential for $\mathrm{C}_{2} \mathrm{~F}_{5}$ is not within the scope of the present article.

A high-energy pathway of $\mathrm{C}_{2} \mathrm{~F}_{4}$ dissociation forming $\mathrm{CF}$ under the present conditions apparently is too endothermic $\left(\Delta H_{0}^{\circ}=160.5 \mathrm{~kJ} \mathrm{~mol}^{-1}\right.$, see the MEP potential of Fig. S13 of the $\mathrm{ESI} \dagger)$. On the other hand, the exothermic pathway $\mathrm{CF}_{3}+\mathrm{CF}_{3} \rightarrow$ $\mathrm{CF}_{2}+\mathrm{CF}_{4}\left(\Delta H_{0}^{\circ}=-181.2 \mathrm{~kJ} \mathrm{~mol}^{-1}\right)$, followed by reaction (5) i.e. by $\mathrm{CF}_{2}+\mathrm{CF}_{3} \rightarrow \mathrm{CF}+\mathrm{CF}_{4}\left(\Delta H_{0}^{\circ}=-25.4 \mathrm{~kJ} \mathrm{~mol}^{-1}\right)$, could also lead to $\mathrm{CF}$ (see the MEP potential for $\mathrm{CF}_{3}+\mathrm{CF}_{3}$ in the ESI, $\dagger$ Fig. S14). The formation of some $\mathrm{CF}$ in the decomposition mechanism thus also appears possible. It should finally be mentioned that absorption-time profiles like Fig. 4 were also observed in the study of the decomposition of $\mathrm{CF}_{3} \mathrm{I}$ (see Fig. 6 of ref. 10); these signals were tentatively attributed to the formation of IF. However, an interpretation analogous to that from the present work presents a more attractive alternative. If $\mathrm{CF}$ is formed, besides the dimerization $2 \mathrm{CF} \rightarrow \mathrm{C}_{2} \mathrm{~F}_{2}$ a reaction $2 \mathrm{CF} \rightarrow \mathrm{C}_{2} \mathrm{~F}+\mathrm{F}$ should also be considered (see details in $\mathrm{ESI} \dagger$-III).

Besides pathways for CF formation and rates for CF dimerization, we also modelled the bimolecular reactions (6) and (7) between the parent $\mathrm{C}_{2} \mathrm{~F}_{5} \mathrm{I}$ and its dissociation products $\mathrm{C}_{2} \mathrm{~F}_{5}$ and $\mathrm{I}$. These reactions could be important for higher reactant concentrations and they were used for the observation of the $\mathrm{C}_{2} \mathrm{~F}_{5} \mathrm{I}$ decomposition reaction by detection of $\mathrm{I}_{2}$ in ref. 13, see above. Reaction (6) could proceed on the two exothermic pathways

$$
\mathrm{C}_{2} \mathrm{~F}_{5}+\mathrm{C}_{2} \mathrm{~F}_{5} \mathrm{I} \rightarrow \mathrm{C}_{2} \mathrm{~F}_{6}+\mathrm{CF}_{3} \mathrm{CFI} \quad\left(\Delta H_{0}^{\circ}=-46.1 \mathrm{~kJ} \mathrm{~mol}^{-1}\right)
$$

$$
\mathrm{C}_{2} \mathrm{~F}_{5}+\mathrm{C}_{2} \mathrm{~F}_{5} \mathrm{I} \rightarrow \mathrm{C}_{2} \mathrm{~F}_{6}+\mathrm{CF}_{2} \mathrm{CF}_{2} \mathrm{I} \quad\left(\Delta H_{0}^{\circ}=0.84 \mathrm{~kJ} \mathrm{~mol}^{-1}\right)
$$

but in both cases high energy barriers TS are involved. The calculations described in the ESI $\dagger$ led to activation enthalpies of $164.8 \mathrm{~kJ} \mathrm{~mol}^{-1}$ for reaction (12) and $181.1 \mathrm{~kJ} \mathrm{~mol}^{-1}$ for reaction (13). TST calculations of the rate constants were represented by

$$
k_{12} \approx 2.7 \times 10^{10}(T / 1000 \mathrm{~K})^{3.1} \exp (-1985 \mathrm{~K} / T) \mathrm{cm}^{3} \mathrm{~mol}^{-1} \mathrm{~s}^{-1}
$$

$k_{13} \approx 1.2 \times 10^{11}(T / 1000 \mathrm{~K})^{3.1} \exp (-21850 \mathrm{~K} / T) \mathrm{cm}^{3} \mathrm{~mol}^{-1} \mathrm{~s}^{-1}$

corresponding to $k_{12}=6.5 \times 10^{1} \mathrm{~cm}^{3} \mathrm{~mol}^{-1} \mathrm{~s}^{-1}$ and $k_{13}=4.0 \times$ $10^{1} \mathrm{~cm}^{3} \mathrm{~mol}^{-1} \mathrm{~s}^{-1}$ at $T=1000 \mathrm{~K}$. In contrast to these reactions, for reaction (7) between $\mathrm{I}$ and $\mathrm{C}_{2} \mathrm{~F}_{5} \mathrm{I}$ no activation barrier was found beyond the endothermicity. This is consistent with the experiments of ref. 11, 12, and 46 which determined an activation energy close to zero for the reverse reaction 
$\mathrm{I}_{2}+\mathrm{C}_{2} \mathrm{~F}_{5} \rightarrow \mathrm{I}+\mathrm{C}_{2} \mathrm{~F}_{5} \mathrm{I}$. Converting the experimental results for this reaction with the equilibrium constants led to

$$
k_{7} \approx 3.6 \times 10^{13} \exp (-7460 \mathrm{~K} / T) \mathrm{cm}^{3} \mathrm{~mol}^{-1} \mathrm{~s}^{-1}
$$

corresponding to $k_{7} \approx 2 \times 10^{10} \mathrm{~cm}^{3} \mathrm{~mol}^{-1} \mathrm{~s}^{-1}$ at $T=1000 \mathrm{~K}$. Clearly reaction (6) thus can be neglected, while reaction (7) must be accounted for in experiments using larger concentrations than those of the present work.

\section{Analysis of experimental absorption profiles}

As emphasized before, the analysis of experimental absorptiontime profiles is greatly facilitated by the modelling results described in the two previous sections. In the following this will be demonstrated for the shown examples of experimental signals. As the considered dissociation and the reverse recombination reactions are all in their falloff ranges, the falloff expressions from ref. 39-41 for the [Ar]-dependence of the rate constants were used. The required falloff parameters and equilibrium constants $K_{\mathrm{i}, \mathrm{c}}$ were taken from Tables 2 and 3.

For the lowest temperatures of the present study (and the given [Ar]), $k_{1}$ exceeds $k_{2}\left(e . g ., k_{1}=6.7 \times 10^{2} \mathrm{~s}^{-1} v s . k_{2}=2.0 \times 10^{2} \mathrm{~s}^{-1}\right.$ for Fig. 5). The signal of Fig. 5 at $280 \mathrm{~nm}$, therefore, is dominated by the faster decay of $\mathrm{C}_{2} \mathrm{~F}_{5} \mathrm{I}$ and not by the much slower formation of $\mathrm{CF}_{2}$. Fig. 5 includes a modelled absorption-time profile, accounting for the contributions from $\mathrm{C}_{2} \mathrm{~F}_{5} \mathrm{I}$ and $\mathrm{CF}_{2}$. In spite of the superposition of the two absorptions, signals like Fig. 5 can be used to derive experimental values of $k_{1}$ independent of the precise value of $k_{2}$. One should note, however, that in later stages of the reaction one must account for the onset of the recombination reaction (8), i.e. of $\mathrm{C}_{2} \mathrm{~F}_{5}+\mathrm{I} \rightarrow \mathrm{C}_{2} \mathrm{~F}_{5} \mathrm{I}$. This can be done with the help of the equilibrium constant $K_{1, \mathrm{c}}$ given in Table 2 . Within the relatively large experimental uncertainty (because of the superposition of the two absorptions estimated to be about a factor of two), the derived values of $k_{1}$ agree with the [Ar]dependent modelling results such as illustrated by the Arrhenius plot of Fig. 8. An improved fit was obtained (both in Fig. 5 and 8) if $\Delta H_{0}^{\circ}$ was increased from the value calculated in the present work (see the ESI $\dagger$ ) by about $5 \mathrm{~kJ} \mathrm{~mol}^{-1}$. One should mention one further complication: according to the equilibrium constants from Table 2, one would have expected a dissociation of only a few percent of $\mathrm{C}_{2} \mathrm{~F}_{5} \mathrm{I}$ until equilibrium in Fig. 5 is reached whereas the signal decays to smaller values. This observation, however, is explained by the onset of reactions (2) and (5), and possibly some contribution from reaction (6).

Observations at $268.5 \mathrm{~nm}$, such as illustrated in Fig. 1, like in Fig. 5 are characterized by the superposition of absorptions from $\mathrm{C}_{2} \mathrm{~F}_{5} \mathrm{I}$ and $\mathrm{CF}_{2}$. As the absorption cross sections of both species are known (see Table 1 ), the signals nevertheless can be simulated. With the modelled values for $k_{1}$ and $k_{2}$ (as well as the other rate constants from Table 1 , in particular $k_{3}$ ), results such as included in Fig. 1 are obtained, validating the given interpretation of the signals.

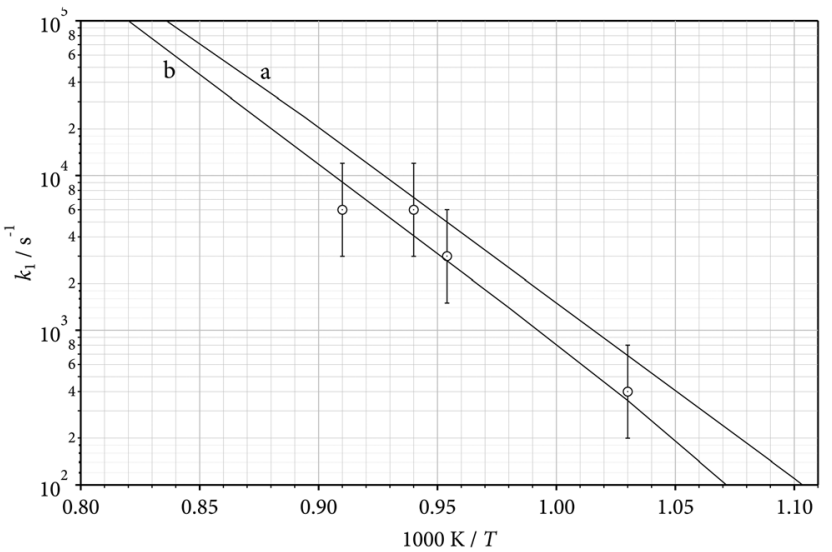

Fig. 8 Pseudo-first order rate constants $k_{1}$ of the unimolecular dissociation of $\mathrm{C}_{2} \mathrm{~F}_{5}$ l at $[\mathrm{Ar}]=1.4 \times 10^{-4} \mathrm{~mol} \mathrm{~cm}{ }^{-3}$ (full line: modelling results from Tables 1-3, curve a for $\Delta H_{0}^{\circ}=234 \mathrm{~kJ} \mathrm{~mol}^{-1}$, curve b for $\Delta H_{0}^{\circ}=239 \mathrm{~kJ} \mathrm{~mol}^{-1}$; symbols: examples of experimental results from the present work with estimated error bars, see text)

At $248 \mathrm{~nm}$ the absorption cross section of $\mathrm{CF}_{2}$ by far exceeds that of $\mathrm{C}_{2} \mathrm{~F}_{5} \mathrm{I}$. As $\mathrm{C}_{2} \mathrm{~F}_{5} \mathrm{I}$ decomposes much more rapidly than $\mathrm{CF}_{2}$, the formation and consumption of the latter species can well be studied without interference from $\mathrm{C}_{2} \mathrm{~F}_{5} \mathrm{I}$. Assuming that one $\mathrm{C}_{2} \mathrm{~F}_{5}$ is produced per one dissociating $\mathrm{C}_{2} \mathrm{~F}_{5} \mathrm{I}$, the initial rise of the $\mathrm{CF}_{2}$ signal can be attributed to $\mathrm{CF}_{2}$ formation by reaction (2) alone. The modelling of the complete mechanism also allows one to predict the maximum of the signal. With reactions (1)-(4) one predicts a larger signal than observed. This can be attributed to reaction (5) which efficiently converts $\mathrm{CF}_{2}$ and $\mathrm{CF}_{3}$ into the less active species $\mathrm{CF}$ and $\mathrm{CF}_{4}$. The reduction of the maximum of the signals allows one to fit $k_{5}$. One obtains values of the order of the limiting high pressure rate constant for the recombination of $\mathrm{CF}_{2}$ and $\mathrm{CF}_{3}$ forming $\mathrm{C}_{2} \mathrm{~F}_{5}$ (e.g., for Fig. 2, $k_{5} \approx 2 \times k_{-2, \infty}$ where $k_{-2, \infty}=k_{2, \infty} / K_{2, \mathrm{c}}$; unfortunately the fit of $k_{5}$ is markedly influenced by uncertainties in $k_{1}, k_{2}, k_{3}$, and $k_{4}$, such that more precise determinations have to wait for studies in simpler reaction systems; so far the uncertainty of $k_{5}$ is estimated to be about a factor of 4 ).

The contribution of reaction (5) weakens when the reactant concentration is further decreased. Fig. 3 shows an example with a reactant concentration as low as about $100 \mathrm{ppm}$. The mechanism here indeed is dominated by reactions (1)-(4). Measurements at $248 \mathrm{~nm}$ were also performed behind incident shock waves, such that [Ar] could be varied between $2 \times 10^{-5}$ and $2 \times 10^{-4} \mathrm{~mol} \mathrm{~cm}^{-3}$. The comparison between experimental and modelled rate constants in the falloff range of reaction (2) is illustrated in Fig. 9 for low and high [Ar]. An agreement with the modelled rate constants within about a factor of 2 was obtained, similar to that of Fig. 8 .

While the signals of Fig. 1, 3 and 5 could well be modelled with the data from Tables 1-3 and fitted values of $k_{5}$, the modelling of Fig. 4 met with difficulties. Although the time dependence of the increasing signal at $200 \mathrm{~nm}$ corresponds well to the formation of $\mathrm{C}_{2} \mathrm{~F}_{4}$ by the dimerization reaction (3), the signal is larger than explained by $\mathrm{C}_{2} \mathrm{~F}_{4}$ formation alone. Obviously, there is an important, additional, contribution to 


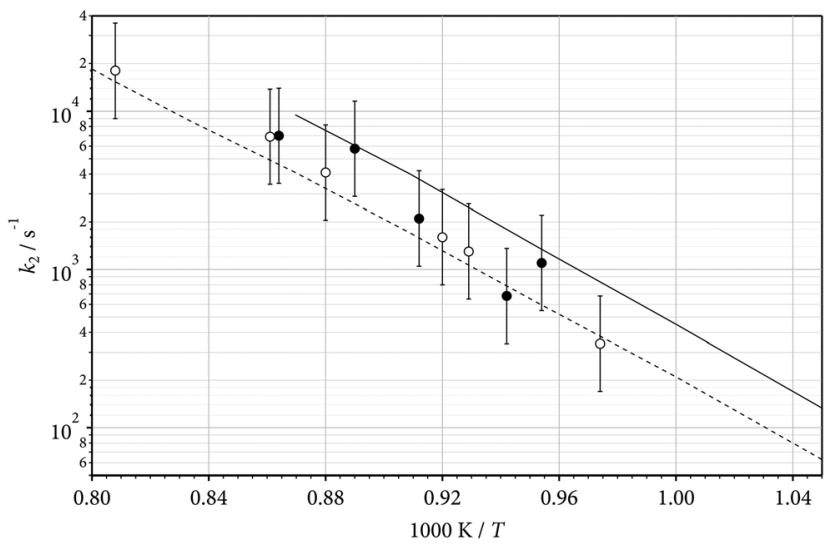

Fig. 9 Pseudo-first order rate constants $k_{2}$ of the unimolecular dissociation of $\mathrm{C}_{2} \mathrm{~F}_{5}$ (2) (full line: modelling results for $[\mathrm{Ar}]=1.5 \times 10^{-4} \mathrm{~mol} \mathrm{~cm}^{-3}$, dashed line: modelling results for $[\mathrm{Ar}]=2.8 \times 10^{-5} \mathrm{~mol} \mathrm{~cm}^{-3}$, see Table 2 and ref. 7; symbols: experimental results from the present work with estimated error bars, see text; open circles for $[\mathrm{Ar}]=2.8 \times 10^{-5} \mathrm{~mol} \mathrm{~cm}^{-3}$ filled circles for $[\mathrm{Ar}]=1.5 \times 10^{-4} \mathrm{~mol} \mathrm{~cm}^{-3}$ ).

the signal from the strong absorber CF formed by reaction (5). As only upper limits of the absorption cross section of CF at $200 \mathrm{~nm}$ are available (for temperatures near $2000 \mathrm{~K}$ ) and more precise values of $k_{5}$ are needed, a modelling of the signal of Fig. 4 does not yet appear warranted. This also concerns the "irregularities" of the signal after about $1 \mathrm{~ms}$ (mentioned for Fig. 2 above; one should also mention that the step of the signal at the arrival of the reflected shock wave is due to $\mathrm{C}_{2} \mathrm{~F}_{5} \mathrm{I}$ from an absorption band located at wavelengths below $200 \mathrm{~nm}^{23}$ ). Because of these complications, the present reaction system did not appear suitable for further studies of CF reactions.

\section{Conclusions}

The described UV absorption study has provided insight into the dissociation mechanism of $\mathrm{C}_{2} \mathrm{~F}_{5}$ I. It has allowed us to analyze the absorption-time profiles of the dissociating $\mathrm{C}_{2} \mathrm{~F}_{5} \mathrm{I}$ and of reaction products like $\mathrm{CF}, \mathrm{CF}_{2}$ and $\mathrm{C}_{2} \mathrm{~F}_{4}$. As the absorptions of these species are all superimposed, modelled rate constants and separately determined absorption cross sections facilitated the analysis of the recorded signals. The diversity of the signals allowed for a validation of the modelled rate constants and the decomposition mechanism. The detection of iodine atoms by ARAS (atomic resonance absorption spectroscopy) like in ref. 3 and 4 (studying the dissociations of $\mathrm{CF}_{3} \mathrm{I}$ and $\mathrm{C}_{3} \mathrm{~F}_{7} \mathrm{I}$ ), would have allowed to work with even lower reactant concentrations than the present UV absorption technique and provided a more direct access to the unimolecular dissociation of $\mathrm{C}_{2} \mathrm{~F}_{5} \mathrm{I}$. However, monitoring UV absorption signals of other species at higher reactant concentrations has provided insight into the decomposition mechanism and its secondary reactions.

A number of points deserve particular mention: (i) even under the low concentration conditions of the present work, the reverse of all dissociation reactions had to be included; (ii) falloff effects of all dissociation and recombination reactions had to be accounted for; (iii) the dominant absorption contributions came from $\mathrm{C}_{2} \mathrm{~F}_{5} \mathrm{I}, \mathrm{CF}_{2}, \mathrm{C}_{2} \mathrm{~F}_{4}$, and $\mathrm{CF}$, however, with relative importance varying with wavelength and temperature; (iv) $\mathrm{CF}$ probably was formed by a roaming radical process $\mathrm{CF}_{2}+\mathrm{CF}_{3} \rightarrow \mathrm{CF}+\mathrm{CF}_{4}$ (5) bypassing the bound $\mathrm{C}_{2} \mathrm{~F}_{5}$ intermediate (with a rate constant of the order of, but somewhat larger than, the limiting high pressure rate constant for the recombination of $\mathrm{CF}_{2}$ and $\mathrm{CF}_{3}$ forming $\mathrm{C}_{2} \mathrm{~F}_{5}$ ); (v) $\mathrm{CF}$ apparently dimerizes to $\mathrm{C}_{2} \mathrm{~F}_{2}$. (vi) besides I atoms, the most stable end products of the decomposition under the conditions of the described work probably are $\mathrm{CF}_{4}$ and $\mathrm{C}_{2} \mathrm{~F}_{2}$.

The present study illustrates again the benefit of combining kinetic measurements with rate constant modellings. Experimentally determined rate constants for the dissociations of $\mathrm{C}_{2} \mathrm{~F}_{5} \mathrm{I}$ and $\mathrm{C}_{2} \mathrm{~F}_{5}$ were shown to agree well with modelled values which then validates the use of the modelled rate constants for extrapolation into unexplored ranges.

\section{Conflicts of interest}

There are no conflicts to declare.

\section{Acknowledgements}

Financial support of this work by the Deutsche Forschungsgemeinschaft (Project TR 69/21-3) is gratefully acknowledged. Open Access funding provided by the Max Planck Society.

\section{References}

1 S. Solomon, J. B. Burkholder, A. R. Ravishankara and R. R. Garcia, Ozone Depletion and Global Warming Potentials of $\mathrm{CF}_{3} \mathrm{I}$, J. Geophys. Res., 1994, 99, 20.929-20.935.

2 Yu. N. Shebeko, V. V. Azatyan, I. A. Bolodian, V. Y. Navzenya, S. N. Koyplov, D. Y. Shebeko and E. D. Zamishevski, The Influence of Fluorinated Hydrocarbons on the Combustion of Gaseous Mixtures in a Closed Vessel, Combust. Flame, 2000, 121, 542-547.

3 N. S. Bystrov, A. V. Emelianov, A. V. Eremin and P. I. Yatsenko, Direct Measurements of Rate Coefficients for Thermal Decomposition of $\mathrm{CF}_{3} \mathrm{I}$ using Shock-Tube ARAS technique, J. Phys. D: Appl. Phys., 2018, 51, 1-8.

4 N. S. Bystrov, A. V. Emelianov, A. V. Eremin, B. Loukhovitski, A. Sharipov and P. I. Yatsenko, Direct Measurements of $\mathrm{C}_{3} \mathrm{~F}_{7} \mathrm{I}$ Dissociation Rate Constant using a Shock-Tube ARAS technique, Int. J. Chem. Kinet., 2019, 51, 206-214.

5 E. Goos, A. Burcat and B. Ruscic, Extended Third Millenium Ideal Gas and Condensed Phase Thermochemical Database for Combustion with Updates from Active Thermochemical Tables. http://burcat.technion.ac.il/div September 2005, January 2015.

6 J. B. Burkholder, J. P. D. Abbatt, R. E. Huie, M. J. Kurylo, D. M. Wilmouth, S. P. Sander, J. R. Barker, C. E. Kolb, V. L. Orkin and P. H. Wine, Chemical Kinetics and Photochemical Data for Use in Atmospheric Studies Evaluation 
Number 18, JPL Publication 15 - 10 2015, Jet Propulsion Laboratory, Pasadena.

7 C. J. Cobos, K. Hintzer, L. Sölter, E. Tellbach, A. Thaler and J. Troe, Shock Wave and Modelling Study of the Dissociation Pathways of $\left(\mathrm{C}_{2} \mathrm{~F}_{5}\right)_{3} \mathrm{~N}$, Phys. Chem. Chem. Phys., 2019, 21, 9785-9792.

8 K. Li, E. M. Kennedy and B. Z. Dlugogorski, Experimental and Computational Studies of the Pyrolysis of $\mathrm{CBrF}_{3}$, and the Reaction of $\mathrm{CBrF}_{3}$ with $\mathrm{CH}_{4}$, Chem. Eng. Sci., 2000, 55, 4067-4078.

9 S. S. Kumaran, M.-C. Su, K. P. Lim and J. V. Michael, Thermal Decomposition of $\mathrm{CF}_{3} \mathrm{I}$ using I-atom Absorption, Chem. Phys. Lett., 1995, 243, 59-63.

10 C. J. Cobos, L. Sölter, E. Tellbach and J. Troe, Falloff Curves and Mechanism of Thermal Decomposition of $\mathrm{CF}_{3} \mathrm{I}$ in Shock Waves, Phys. Chem. Chem. Phys., 2019, 21, 23892-23899.

11 S. L. Dobychin, V. I. Mashendzhinov, V. I. Mishin, V. N. Semenov and V. S. Shpak, Kinetics of Thermal Decomposition of Perfluoroalkyl Iodides and D(R-I) Binding Energy, $\mathrm{R}=\mathrm{CF}_{3}, \mathrm{C}_{2} \mathrm{~F}_{5}, \mathrm{n}-\mathrm{C}_{3} \mathrm{~F}_{7}$, iso- $\mathrm{C}_{3} \mathrm{~F}_{7}, n-\mathrm{C}_{4} \mathrm{~F}_{9}$, tert- $\mathrm{C}_{4} \mathrm{~F}_{9}$, Dokl. Akad. Nauk SSSR, 1990, 312, 1166-1168.

12 G. A. Skorobogatov, B. P. Dymov and V. K. Khripun, Determination of Rate Constants and Equilibrium Constants of $\mathrm{RI} \leftrightarrow \mathrm{R}+\mathrm{I}$ and $\mathrm{I}+\mathrm{RI} \leftrightarrow \mathrm{I}_{2}+\mathrm{R}$ for $\mathrm{R}=\mathrm{CF}_{3}, \mathrm{C}_{2} \mathrm{~F}_{5}$, or $\mathrm{C}_{4} \mathrm{~F}_{9}$, Kinet. Katal., 1991, 32, 252-259.

13 I. S. Zaslonko, Yu. K. Mukoseev, G. A. Skorobogatov, V. N. Smirnov and V. K. Khripun, Rate Constant of Thermal Dissociation of Gaseous $\mathrm{C}_{2} \mathrm{~F}_{5} \mathrm{I}$, Kinet. Katal., 1991, 32, 468-473.

14 W. H. Pence, S. L. Baughcum and S. R. Leone, Laser UV Photofragmentation of Halogenated Molecules. Selective Bond Dissociation and Wavelength-Specific Quantum Yields for Excited $\mathrm{I}\left({ }^{2} \mathrm{P}_{1 / 2}\right)$ and $\operatorname{Br}\left({ }^{2} \mathrm{P}_{1 / 2}\right)$ Atoms, J. Phys. Chem., 1981, 85, 3844-3851.

15 D. Krajnovich, L. J. Butler and Y. T. Lee, UV Photodissociation of $\mathrm{C}_{2} \mathrm{~F}_{5} \mathrm{Br}, \mathrm{C}_{2} \mathrm{~F}_{5} \mathrm{I}$, and 1,2- $\mathrm{C}_{2} \mathrm{~F}_{4} \mathrm{BrI}$, J. Phys. Chem., 1984, 81, 3031-3047.

16 A. V. Baklanov, M. Aldener, B. Lindgren and U. Sassenberg, R2PI Detection of the Quantum Yields of $\mathrm{I}\left({ }^{2} \mathrm{P}_{1 / 2}\right)$ and $\mathrm{I}\left({ }^{2} \mathrm{P}_{3 / 2}\right)$ in the Photodissociation of $\mathrm{C}_{2} \mathrm{~F}_{5} \mathrm{I}, n-\mathrm{C}_{3} \mathrm{~F}_{7} \mathrm{I}, i-\mathrm{C}_{3} \mathrm{~F}_{7} \mathrm{I}$ and $\mathrm{CH}_{3} \mathrm{I}$, Chem. Phys. Lett., 2000, 325, 399-404.

17 A. V. Baklanov, G. A. Bogdanchikov, M. Aldener, U. Sassenberg and A. Persson, Nanosecond and Femtosecond Probing of the Dynamics of the UV-photodissociation of Perfluoroethyliodide $\mathrm{C}_{2} \mathrm{~F}_{5} \mathrm{I}$, J. Chem. Phys., 2001, 115, 11157-11165.

18 K. Hohla and K. L. Kompa, in Handbook of Chemical Lasers, ed. R. W. F. Gross and J. F. Bott, Wiley, New York, 1976.

19 G. A. Skorobogatov, Chemical Processes in Active Volume of Photodissociative Iodine Laser, Czech. J. Phys., 1991, 41, 1189-1203.

20 D. Zhong and A. H. Zewail, Femtosecond Real-Time Probing of Reactions. 23. Studies of Temporal, Velocity, Angular, and State Dynamics from Transition States to Final Products by Femtosecond-Resolved Mass Spectrometry, J. Phys. Chem. A, 1998, 102, 4031-4058.

21 A. M. Velichko, E. B. Gordon, A. A. Nadeikin, A. I. Nikitin and V. L. Tal'roze, Multiphoton Dissociation and Fragmentation of $\mathrm{C}_{2} \mathrm{~F}_{5} \mathrm{I}$, High Energ. Chem., 1986, 20, 468-471.
22 G. A. Skorobogatov, V. G. Seleznev and O. N. Slesar, Method of Overlapping Relaxations Measurement of the Absolute Rate Constants of Competing Reactions of a $\mathrm{C}_{n} \mathrm{~F}_{2 n+1}$ Radical and $\mathrm{I}\left({ }^{2} \mathrm{P}_{1 / 2}\right), \mathrm{I}\left({ }^{2} \mathrm{P}_{3 / 2}\right)$ Atoms in the Gas Phase, Dokl. Phys. Chem., 1976, 231, 1292-1295.

23 C. J. Cobos, K. Hintzer, L. Sölter, E. Tellbach, A. Thaler and J. Troe, Shock Wave and Modelling Study of the UV Spectra of Perfluorocarbon Iodide and Perfluorocarbon Radicals, Combust. Flame, 2021, 224, 177-182.

24 C. J. Cobos, G. Knight, L. Sölter, E. Tellbach and J. Troe, Kinetic and Spectroscopic Studies of the Reaction of $\mathrm{CF}_{2}$ with $\mathrm{H}_{2}$ in Shock Waves, J. Phys. Chem. A, 2017, 121, 7827-7834.

25 L. Brouwer and J. Troe, Shock Wave Study of the UV Spectrum of $\mathrm{CF}_{3} \mathrm{I}$, Chem. Phys. Lett., 1981, 82, 1-4.

26 K. Glänzer, M. Maier and J. Troe, Shock-Wave Study of the High-Temperature UV Absorption and the Recombination of $\mathrm{CF}_{3}$ Radicals, J. Phys. Chem., 1980, 84, 1681-1686.

27 C. J. Cobos, A. E. Croce, K. Luther, L. Sölter, E. Tellbach and J. Troe, Experimental and Modeling Study of the Reaction $\mathrm{C}_{2} \mathrm{~F}_{4}(+\mathrm{M}) \leftrightarrow \mathrm{CF}_{2}+\mathrm{CF}_{2}(+\mathrm{M})$, J. Phys. Chem. A, 2013, 117, 11420-11429.

28 C. J. Cobos, G. Knight, L. Sölter, E. Tellbach and J. Troe, Experimental and Modeling Study of the Multichannel Thermal Decomposition of $\mathrm{CH}_{3} \mathrm{~F}$ and $\mathrm{CH}_{2} \mathrm{~F}$, Phys. Chem. Chem. Phys., 2018, 20, 2627-2636.

29 C. J. Cobos, L. Sölter, E. Tellbach and J. Troe, Shock Wave Study of the Thermal Dissociations of $\mathrm{C}_{3} \mathrm{~F}_{6}$ and $c-\mathrm{C}_{3} \mathrm{~F}_{6}$. II. Dissociation of Hexafluorocyclopropane and Dimerization of $\mathrm{CF}_{2}$, J. Phys. Chem. A, 2014, 118, 4873-4879.

30 C. J. Cobos, A. E. Croce, K. Luther and J. Troe, Temperature and Pressure Dependence of the Reaction $2 \mathrm{CF}_{3}(+\mathrm{M}) \leftrightarrow$ $\mathrm{C}_{2} \mathrm{~F}_{6}(+\mathrm{M})$, J. Phys. Chem. A, 2010, 114, 4748-4754.

31 C. J. Cobos, A. E. Croce, K. Luther and J. Troe, Experimental and Modelling Study of the Unimolecular Thermal Dissociation of $\mathrm{CHF}_{3}$, Z. Phys. Chem., 2011, 225, 1019-1028.

32 C. J. Cobos, A. E. Croce, K. Luther and J. Troe, Shock Wave Study of the Thermal Decomposition of $\mathrm{CF}_{3}$ and $\mathrm{CF}_{2}$ Radicals, J. Phys. Chem. A, 2010, 114, 4755-4761.

33 C. J. Cobos, G. Knight, L. Sölter, E. Tellbach and J. Troe, Falloff Curves of the Reaction $\mathrm{CF}_{3}(+\mathrm{M}) \rightarrow \mathrm{CF}_{2}+\mathrm{F}(+\mathrm{M})$, J. Phys. Chem. A, 2020, 124(7), 1235-1239.

34 G. Knight, L. Sölter, E. Tellbach and J. Troe, Shock Wave and Modeling Study of the Reaction $\mathrm{CF}_{4}(+\mathrm{M}) \leftrightarrow \mathrm{CF}_{3}+\mathrm{F}(+\mathrm{M})$, Phys. Chem. Chem. Phys., 2016, 18, 17592-17596.

35 R. N. Hazeldine, Studies in Spectroscopy. Part III. the Ultra-violet Absorption Spectra of Halogen-containing aliphatic Iodo-compounds, and the Relative Stability of Free Halogen-containing Alkyl Radicals, J. Chem. Soc., 1953, 1764-1771.

36 L. Zhang, W. Fuss and K. L. Kompa, Bond-Selective Photodissociation of $\mathrm{CX}(\mathrm{X}=\mathrm{Br}, \mathrm{I})$ in $\mathrm{XC}_{2} \mathrm{H}_{4} \mathrm{C}_{2} \mathrm{~F}_{4} \mathrm{X}$, Chem. Phys, 1990, 144, 289-297.

37 A. I. Maergoiz, E. E. Nikitin, J. Troe and V. G. Ushakov, Classical Trajectory and Statistical Adiabatic Channel 
Study of the Dynamics of Capture and Unimolecular Bond Fission. V. Valence Interactions between Atoms and Linear Rotors, J. Chem. Phys., 1998, 108, 9987-9998.

38 C. J. Cobos and J. Troe, Theory of Thermal Unimolecular Reactions at High Pressures. II. Analysis of Experimental Results, J. Chem. Phys., 1985, 83, 1010-1015.

39 J. Troe, Predictive Possibilities of Unimolecular Rate Theory, J. Phys. Chem., 1979, 83, 114-126.

$40 \mathrm{~J}$. Troe and V. G. Ushakov, Revisiting Falloff Curves of Thermal Unimolecular Reactions, J. Chem. Phys., 2011, 135(054304), 1-10.

41 J. Troe and V. G. Ushakov, Representation of "Broad" Falloff Curves for Dissociation and Recombination Reactions, Z. Phys. Chem., 2014, 228, 1-10.
42 J. Troe, Theory of Thermal Unimolecular Reactions in the Falloff Range. I. Strong Collision Rate Constants, Ber. Bunsenges. Phys. Chem, 1983, 87, 161-169.

43 N. Herath and A. G. Suits, Roaming Radical Reactions, J. Phys. Chem. Lett., 2011, 2, 642-647.

44 J. M. Bowman and B. C. Shepler, Roaming Radicals, Annu. Rev. Phys. Chem., 2011, 62, 531-553.

45 B. Joalland, Y. Shi, A. Kamasah, A. G. Suits and A. M. Mebel, Roaming Dynamics in Radical Addition-Elimination Reactions, Nat. Commun., 2014, 5(4064), 1-6.

46 E.-C. Wu and R. S. Rodgers, Kinetics of the Gas Phase Reaction of Pentafluoroethyl iodide with Hydrogen Iodide. Enthalpy of Formation of the Pentafluoroethyl Radical and the $\pi$ Bond Dissociation Energy in Tetrafluoroethylene, J. Am. Chem. Soc., 1976, 98, 6112-6115. 